\title{
Использование базальтовой микрофибры в легком бетоне повышенной прочности
}

\author{
Бастрыгина С.В., Конохов Р.В., Беляевский А.Т. \\ Институт химии и технологии редких элементов и минерального сырья им. И.В. Тананаева \\ КНЦ PAH, Anamumbl, s.bastrygina@ksc.ru
}

Аннотация. Изучено влияние базальтовой микрофибры и модифицированной базальтовой микрофибры на прочностные характеристики легкого бетона на пористом заполнителе. Установлено, что наибольший прирост прочности при изгибе (22-24 \%) и сжатии (9-18 \%) как в ранние, так и в поздние сроки твердения обеспечивает состав бетона с $2.5 \%$ содержанием модифицированной базальтовой микрофибры. Изучение микроструктуры фибробетона показало, что волокно фибры сохраняет свою поверхность и не теряет армирующих свойств.

Ключевые слова: базальтовая микрофибра, легкий бетон, прочностные характеристики, микроструктура.

\section{The use of basalt microfiber in lightweight concrete with increased strength}

\author{
Bastrygina S.V., Konokhov R.V., Belyaevsky A.T. \\ Tananaev Institute of Chemistry - Subdivision of the Federal Research Centre "Kola Science Centre of the \\ Russian Academy of Sciences», Apatity, Russia, s.bastrygina@ksc.ru
}

\begin{abstract}
The effect of basalt microfiber and modified basalt microfiber on the strength characteristics of lightweight concrete on a porous aggregate has been studied. It was found that the greatest increase in bending strength $(22-24 \%)$ and compression (9-18\%) both in the early and late periods of hardening is provided by the concrete composition with $2.5 \%$ content of modified basalt microfiber. The study of the microstructure of fiber-reinforced concrete showed that of the fiber retains its surface and does not lose its reinforcing properties.
\end{abstract}

Keywords: basalt microfiber, lightweight concrete, strength characteristics, microstructure.

В настоящее время дисперсное армирование бетонов и растворов волокнами получает все более широкое распространение (Войлоков И.А. и др., 2009; Рабинович Ф. Н., 1989). Номенклатура искусственных волокон-фибр весьма обширна, однако наиболее распространены по сравнению с другими четыре вида армирующих волокнистых материалов: стальные, стеклянные, базальтовые волокна и волокна на основе полипропилена.

В связи с развитием нанотехнологий в армировании бетонов и растворов оформилось новое направление - динамическое дисперсное самоармирование цементного камня. В отличие от традиционного метода дисперсного армирования волокнами данный метод основан на предположении, что введение в растворную смесь наномодифицированных дисперсно-упрочняющих заполнителей приводит к росту в составе цементного камня протяженных кристаллических структур длиной в сотни микрометров, что приводит к соответствующему упрочнению цементного камня.

В качестве такого дисперсно-упрочняющего заполнителя может служить базальтовая микрофибра, модифицированная фуллероидами, нанотрубками, астраленами и др. кластерами углерода. Данные кластеры являются разновидностями аллотропических модификаций углерода, которые при введении в растворную смесь играют роль зародышей структурообразования, наноармирующего элемента, центров зонирования новообразований в матрице (Алаторцева У.В., 2011; Булярский С.В., 2011). В работах (Shan S.P. и др., 2009; Konsta-Gdoutos M.S. и др., 2008) отмечается, что углеродные наноматериалы способны изменять микроструктуру минеральной цементной матрицы за счет увеличения содержания гидросиликатов кальция повышенной плотности и снижения пористости.

Анализ литературных источников (Низина Т. А. и др., 2015; Розина В.Е., 2015) показывает, что чаще всего базальтовая микрофибра находит применение в мелкозернистых бетонах, где в качестве заполнителя используется кварцевый песок. 
Задача исследований заключалась в изучении влияния базальтовой микрофибры на свойства и структуру легкого бетона на мелкозернистом пористом заполнителе.

В качестве армирующего компонента в работе использовали обычную базальтовую микрофибру (БФ) и модифицированную (МБФ) производства ООО «НТЦ прикладных нанотехнологий». Фибра представляет собой промышленный отход измельченной базальтовой фибры (ГОСТ 4640-2011 «Вата минеральная. Технические условия) с параметрами, представленными в таблице 1.

Таблица 1. Основные параметры базальтовой микрофибры (БФ) согласно ТУ 761-014-13800624-2004.

Table 1. Basic parameters of basalt microfiber (BF) according to TU 761-014-13800624-2004.

\begin{tabular}{|l|c|}
\hline \multicolumn{1}{|c|}{ Показатель } & Значение \\
\hline Средний диаметр волокна, мкм & $8-10$ \\
\hline Средняя длина волокна, мкм & $100-500$ \\
\hline $\begin{array}{l}\text { Содержание неволокнистых включений размером } \\
\text { более 0.25 мм, \% по массе }\end{array}$ & не более 10 \\
\hline Насыпная плотность, кг/м & 800 \\
\hline Содержание органических веществ, \% по массе & не более 2 \\
\hline
\end{tabular}

Отличие модифицированной фибры от обычной заключается в присутствии в ее составе наномодификатора фуллероидного типа - астралена в количестве от 0.0001 до $0.01 \%$ от массы фибры в зависимости от назначения армируемой конструкции и пластификатора. Как показано в работе (Белова Т.К. и др., 2015;) введение таких наномодифицированных волокон в растворную смесь способствует значительному упрочнению структуры цементного камня.

Для изготовления бетонных образцов в качестве вяжущего использовали портландцемент CEM I 52.5Н (г. Стерлитамак), соответствующий требованиям ГОСТ 31108-2016 «Цементы общестроительные. Технические условия» и алюмосиликатные микросферы в количестве 20 \% от массы цемента. В качестве пористого заполнителя - обработанные угольной пылью и вспученные при $1150^{\circ} \mathrm{C}$ глинистые сланцы фракции 2.5-5 мм. В качестве добавки, повышающей прочность бетона - шунгизитовую пыль в количестве 10 \% от массы цемента. Для регулирования свойств бетонной смеси использовали пластифицирующую добавку на основе поликарбоксилатного эфира Glenium ${ }^{\circledR}$ 51 в количестве $0.5 \%$ от массы цемента. С целью изучения влияния фибры на прочностные свойства бетона были проведены лабораторные испытания пяти составов: контрольный (без фибры), с обычной фиброй и модифицированной. Количество фибры составляло 0.8 и $2.5 \%$ от массы цемента. Подвижность бетонной смеси оценивали по осадке конуса. Водоцементное отношение бетонной смеси подбиралось опытным путем до установления равной подвижности марки ПЗ.

Равномерное распределение волокон фибры в процессе приготовления бетонной смеси оказывает влияние на однородность физико-механических свойств материала и эффективность дисперсного армирования (Kuder К. И др., 2006; Ponikiewski T., 2009)]. Известно, что бетонная смесь с фибрами склонна к комкованию, что резко ухудшает ее качество и не позволяет добиться надлежащего равномерного распределения и уплотнения материала. Поэтому для приготовления смеси используют различные приемы: вводят фибру в последнюю очередь в предварительно перемешанную смесь цемента, воды и заполнителя или смешивают сначала заполнители и волокна, а затем добавляют цемент и воду. В работе фибра для более равномерного распределения в бетонной смеси предварительно была насыщена водой за сутки до использования. Следует отметить, что, так как модифицированная фибра имела в своем составе пластификатор, это значительно облегчало процесс смачивания, чего не наблюдалось при использовании обычной фибры. Исследование влияния фибры на физико-механические свойства (пределы прочности при изгибе и сжатии, среднюю плотность) и структуру бетона проводилось на образцах-балочках размером 40×40×160 мм и образцахкубиках размером 50×50×50 мм, изготовленных из равноподвижных (маркой по удобоукладываемости П3) смесей. 
Значения прочностных характеристик бетона различных составов при изгибе и сжатии, определяемые в возрасте 7 и 28 сут. приведены в таблице 2 и на рисунках 1 и 2 . Из данных таблицы 2 видно, что введение малого количества фибры $(0.8 \%)$ незначительно влияет на В/Ц отношение. Увеличение объемного содержания фибры до $2.5 \%$ влияет на водопотребность смеси и водоцементное отношение, которое приходится увеличивать для обеспечения заданной удобоукладываемости бетонной смеси, так как возрастает площадь поверхности соприкосновения армирующего компонента с цементной матрицей.

Таблица 2. Прочностные характеристики легкого бетона.

Table 2. Strength characteristics of lightweight concrete.

\begin{tabular}{|c|c|c|c|c|c|c|}
\hline \multirow{2}{*}{$\begin{array}{l}\text { Наименование } \\
\text { состава }\end{array}$} & \multirow[t]{2}{*}{ В/Ц } & \multirow{2}{*}{ 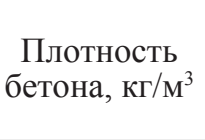 } & \multicolumn{2}{|c|}{$\begin{array}{c}\text { Предел прочности при } \\
\text { изгибе в возрасте..., МПа }\end{array}$} & \multicolumn{2}{|c|}{$\begin{array}{c}\text { Предел прочности при } \\
\text { сжатии в возрасте..., МПа }\end{array}$} \\
\hline & & & 7 суток & 28 суток & 7 суток & 28 суток \\
\hline контрольный & 0.35 & 1520 & 4.43 & 4.87 & 41.5 & 47.5 \\
\hline БФ-0.8 & 0.36 & 1506 & 4.80 & 5.25 & 43.0 & 48.6 \\
\hline БФ-2.5 & 0.40 & 1530 & 5.15 & 5.74 & 47.8 & 51.2 \\
\hline МБФ-0.8 & 0.33 & 1510 & 5.41 & 5.80 & 45.3 & 49.5 \\
\hline МБФ-2.5 & 0.38 & 1536 & 5.48 & 5.94 & 48.8 & 54.0 \\
\hline
\end{tabular}

Анализ результатов исследований, представленных в таблице 2 и на рисунке 1 показывает, что при введении в состав бетона фибры уже на 7-е сутки твердения происходит повышение прочности при изгибе от 8 до $16 \%$ при использовании БФ (0.8 и $2.5 \%$ и о от 22 до $24 \%$ при использовании МБФ (0.8 и $2.5 \%$ п) по сравнению с контрольным составом. Однако, при дальнейшем твердении бетона до 28 сут., прирост прочности остается практически без изменений по сравнению с контрольным составом и составляет 8 и 18 \% при использовании БФ и 19 и $22 \%$ при использовании МБФ. Обращает на себя внимание тот факт, что разница в показателях при использовании 0.8 и $2.5 \%$ модифицированной микрофибры минимальна и составляет не более $2 \%$; при использовании БФ разница составляет около $9 \%$. По сравнению с 7 сут. образцами прочность образцов при изгибе в возрасте 28 сут. увеличилась в среднем на $9 \%$.

Результаты испытаний образцов на прочность при сжатии показали (рис. 2), что введение малых количеств фибры оказывает незначительное влияние на этот показатель. Прирост прочности в

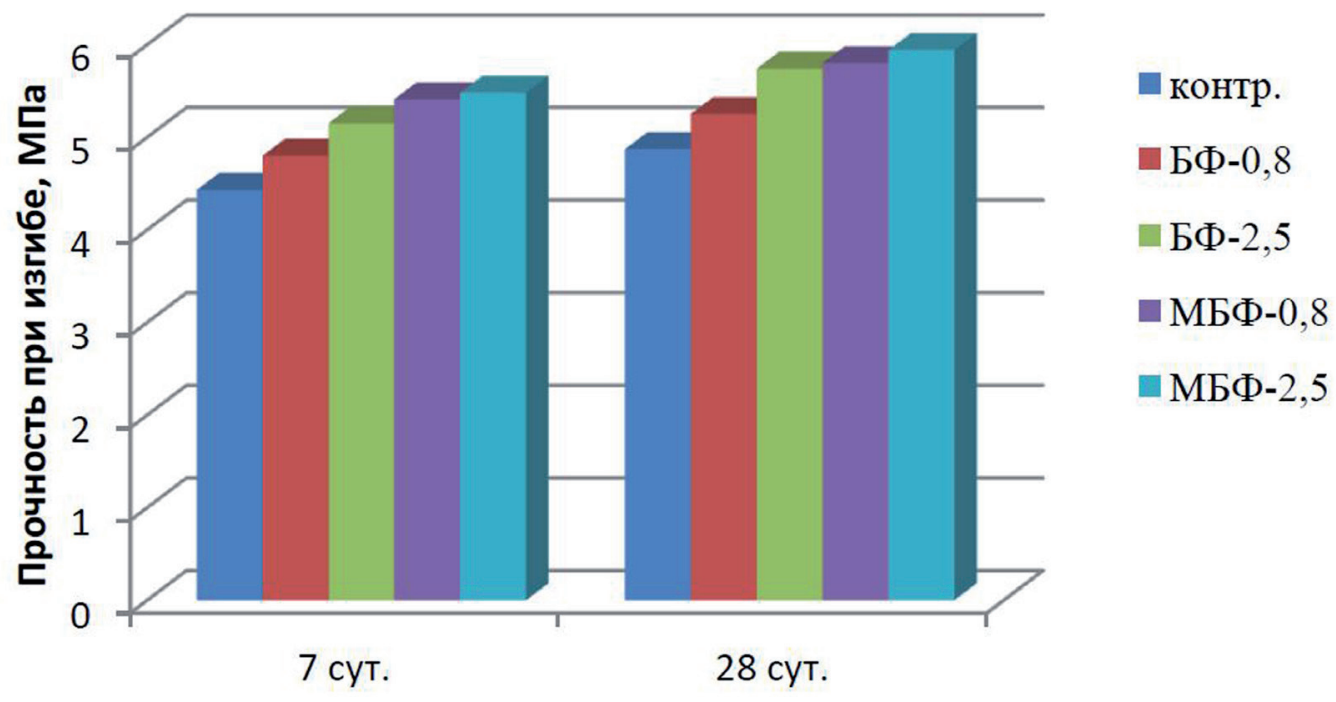

Сроки твердения бетона, сут.

Рис. 1. Прочность образцов при изгибе армированного легкого бетона.

Fig. 1. Flexural Strength of Reinforced Lightweight Concrete. 


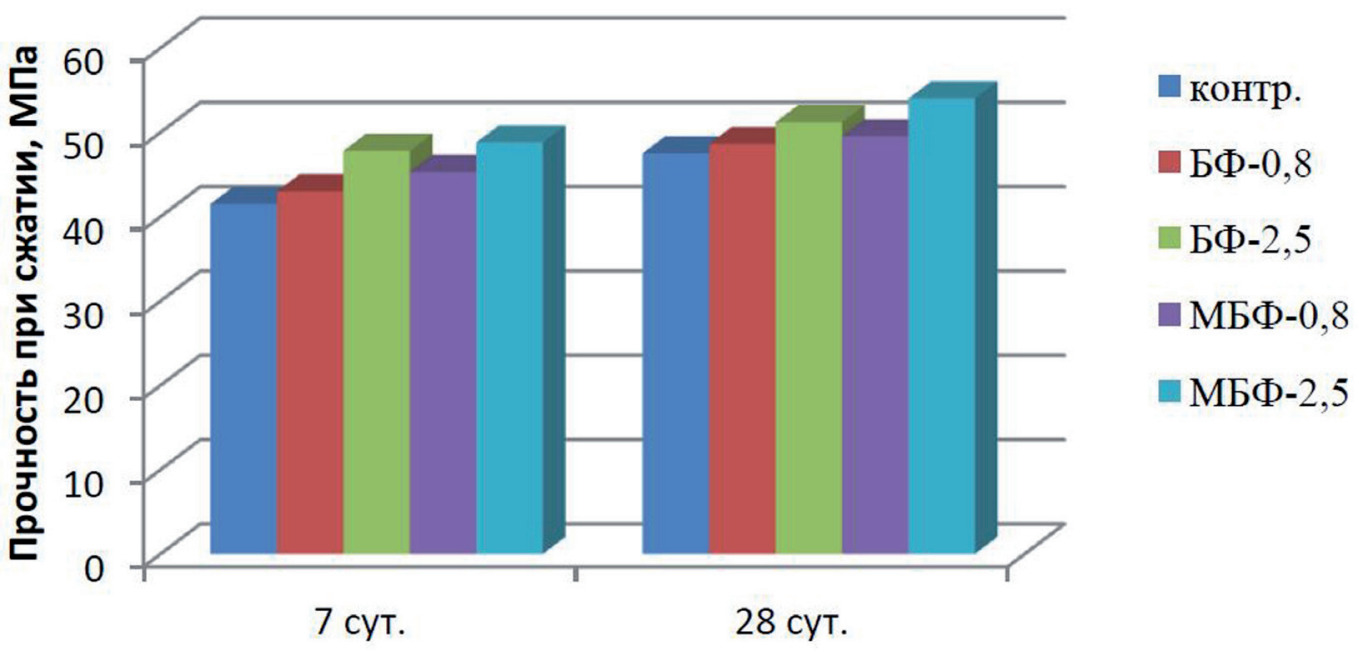

Сроки твердения бетона, сут.

Рис. 2. Прочность образцов при сжатии армированного легкого бетона.

Fig. 2. Strength of samples in compression of reinforced lightweight concrete.

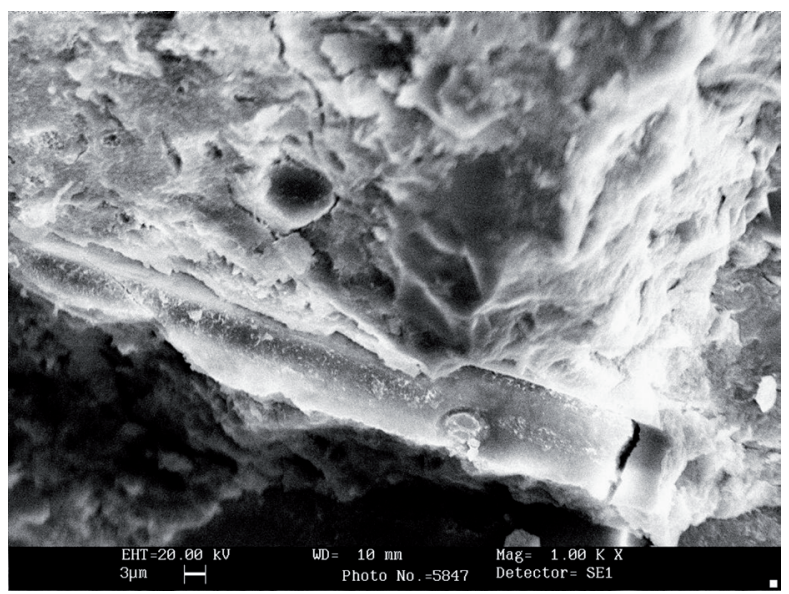

а (увел. 1000)

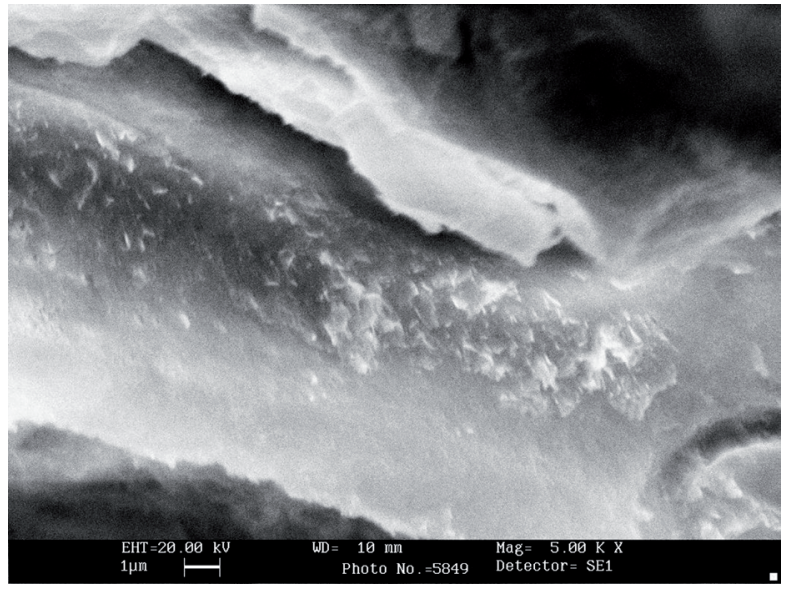

в (увел. 5000)

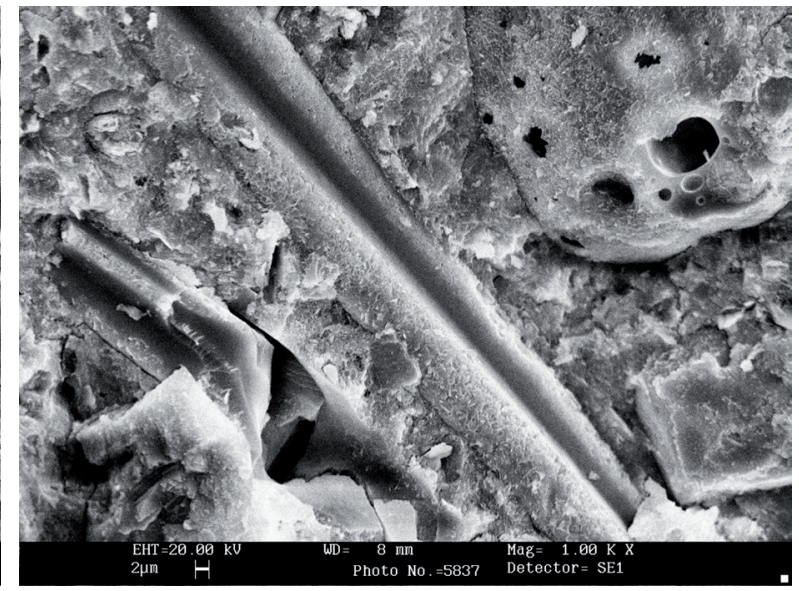

б (увел. 1000)

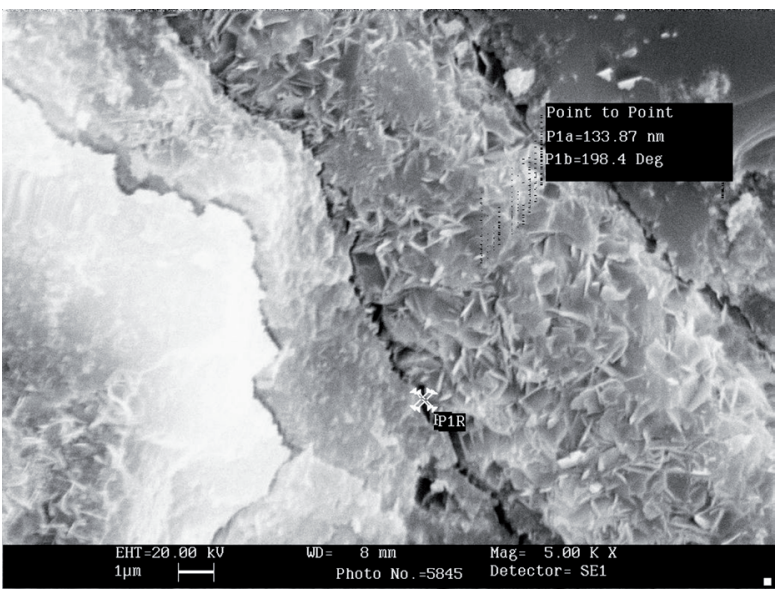

г (увел. 5000)

Рис. 3. Микроструктура легкого, модифицированного микрофиброй бетона в возрасте 28 сут.: а, в - с БФ$2.5 \% ;$ б, г - с МБФ- $2.5 \%$.

Fig. 3 - Microstructure of lightweight, microfiber-modified concrete at the age of 28 days: a, c - with BF-2.5\%; b, $\mathrm{d}-$ with MBF $-2.5 \%$. 
7 сут. возрасте составляет всего 3.6 \% при использовании БФ и 9 \% при использовании МБФ по сравнению с контрольным составом. При повышении количества фибры до 2.5 \% прочность увеличивается на 15 \% при использовании БФ и на $18 \%$ при использовании МБФ. Эта же тенденция сохраняется и при оценке показателей образцов на прочность в 28 сут. возрасте. Наибольшую прочность на сжатие имеют образцы бетона, армированные 2.5 \% фибры.

На основании полученных экспериментальных данных можно сделать вывод, что наибольший прирост прочности при изгибе (+22-24 \%) и сжатии (+9-18\%) как в ранние, так и в поздние сроки твердения показал состав бетона с 2.5 \% содержанием модифицированной базальтовой микрофибры.

Известно, что коррозия базальтовых волокон при действии на них щелочной среды гидратирующегося цемента приводит к снижению их армирующих свойств (Клюев С.В., 2012; Бабаев В.Б. и др., 2013). Для оценки состояния фиброволокна были исследованы сколы бетона с БФ и МБФ в 28 сут. возрасте при различных увеличениях. Фотографии микроструктуры образцов, представленные на рисунке 3 a, б (увеличение 1000) показывают, что волокно фибры сохраняет свою поверхность и не теряет армирующих свойств. При 5000 кратном увеличении сколов видно, что поверхность волокна покрыта большим количеством игольчатых новообразований гидросиликатов кальция. Это говорит о том, что введенная в состав бетона шунгизитовая пыль реагирует с известью, сохраняя тем самым поверхность базальтовой микрофибры неповрежденной. Большее количество новообразований наблюдается у состава, армированного модифицированной базальтовой микрофиброй (рис. 3 г), по сравнению с составом, армированным БФ (рис. 3 в).

Таким образом, результаты исследований свидетельствуют о целесообразности дисперсного армирования легкого бетона модифицированной базальтовой микрофиброй. В дальнейшем работа будет направлена на изучение комплексного влияния полифункциональных модифицирующих добавок и дисперсного армирования на основные физико-механические характеристики легких бетонов, а также анализ наиболее оптимальных комплексов модификаторов и фибр с целью повышения прочностных свойств бетонов.

\section{Литература}

1. Алаторцева У.В. Конструкционные сталефибробетоны, модифицированные комплексными углеродными микро- и наноразмерными добавками: дис. канд. техн. наук: 05.23.05. Волгоград. 2011. 151 с.

2. Бабаев В.Б., Строкова В.В., Нелюбова В.В., Савгир Н.Л. К вопросу о щелочестойкости базальтовой фибры в цементной системе // Вестник БГТУ им. В.Г. Шухова. 2013. № 2. С. 63-67.

3. Белова Т.К., Гурьева В.А., Турчанинов В.И. Исследование влияния дисперсного армирования модифицированным базальтовым микроволокном на прочностные свойства цементного раствора // Электронный научный журнал Инженерный вестник Дона. № 2. 2015. ivdon.ru/ru/magazine/archive/n2y2015/2883

4. Булярский С.В. Углеродные нанотрубки: технология, управление свойствами, применение. Ульяновск. Изд-во: ООО «Стрежень». 2011. 478 с.

5. Войлоков И.А., Канаев С.Ф. Базальтофибробетон. Исторический экскурс // Инженерно-строительный журнал. 2009. № 4. С. 26-31.

6. Клюев С.В. К вопросу применения нескольких видов фибр для дисперсно-армированных бетонов // Вестник БГТУ им. В.Г. Шухова. 2012. № 4. С. 81-83.

7. Konsta-Gdoutos M.S., Metaxa Z.S., Shan S.P. Nanoimaging of highly dispersed carbon nanotube reinforced cement based materials // Seventh International RJLEM Symposium on Fibre Reinforced Concrete: Design and Applications, Chennai, India. 2008. P. 125-131.

8. Kuder K., Ozyurt N., Mu E., Shah S. Rheology of fiber-reinforced cement systems using a custom built rheometer. - Brittle Matrix Composites 8: Proc. 8th Int. Symp. BMC8. - Warsaw: Woodhead Publ. Ltd., ZTUREK, 2006. P. 431-439.

9. Низина Т.А., Балыков А.С. Анализ комплексного влияния модифицирующих добавок и дисперсного армирования на физико-механические характеристики мелкозернистых бетонов // Regional architecture and engineering. 2015. № 4. C. 25-32.

10. Рабинович Ф. Н. Дисперсно армированные бетоны. М. Изд-во: Стройиздат. 1989. 176 с.

11. Розина В.Е. Мелкозернистый базальтофибробетон с нанокремнеземом. Дисс. к.т.н. 05.23.05. Улан-Уде. 2015. $146 \mathrm{c}$.

12. Ponikiewski T. Investigation on random distribution of fibres in cement composites. Brittle Matrix Composites 9: Proc. 9th Int. Symp. BMC9. Warsaw: Woodhead Publ. Ltd., IFTR. 2009. P. 131-138.

13. Shan S.P., Konsta-Gdoutos M.S., Metaxa Z.S., Mondal P. Nanoscale modification of cementious materials. Proceeding of the Third International symposium on nanotechnology in construction. Springer. 2009. P. $125-130$. 